NIST Technical Note 1959

\title{
Defining the Resilience Dividend: Accounting for Co-benefits of Resilience Planning
}

\author{
Juan F. Fung \\ Jennifer F. Helgeson
}

This publication is available free of charge from:

https://doi.org/10.6028/NIST.TN.1959 Standards and Technology U.S. Department of Commerce 


\title{
Defining the Resilience Dividend: Accounting for Co-benefits of Resilience Planning
}

\author{
Juan F. Fung \\ Jennifer F. Helgeson \\ Applied Economics Office \\ Engineering Laboratory
}

This publication is available free of charge from:

https://doi.org/10.6028/NIST.TN.1959

April 2017

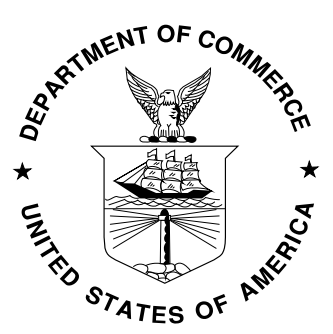

U.S. Department of Commerce Wilbur L. Ross, Jr., Secretary

National Institute of Standards and Technology Kent Rochford, Acting NIST Director and Under Secretary of Commerce for Standards and Technology 
Certain commercial entities, equipment, or materials may be identified in this document in order to describe an experimental procedure or concept adequately. Such identification is not intended to imply recommendation or endorsement by the National Institute of Standards and Technology, nor is it intended to imply that the entities, materials, or equipment are necessarily the best available for the purpose.

National Institute of Standards and Technology Technical Note 1959

Natl. Inst. Stand. Technol. Tech. Note 1959, 40 pages (April 2017) CODEN: NTNOEF

This publication is available free of charge from:

https://doi.org/10.6028/NIST.TN.1959 


\begin{abstract}
This report presents the concept of the resilience dividend as a useful metric for community resilience planning. The report suggests defining the resilience dividend as the net co-benefit (or co-cost) of investing in enhanced resilience, in the absence of a disruptive incident. In order for this definition to be useful, the report reviews literature on co-benefits. The main lessons from this review are that: (1) there is no consensus on the use of the meaning of cobenefit; (2) much of the literature on co-benefits is focused on climate change; and (3) there exist opportunities for the development of co-benefit measurement and assessment methodologies in the context of resilience planning. This report provides guidance and direction on the study and use of the resilience dividend by categorizing the various definitions of co-benefits to provide a frame of reference, reviewing measurement and assessment efforts, and summarizing the review in an annotated bibliography that can serve as a "quick guide" for researchers and practitioners looking for existing work on co-benefits. The report also highlights potential directions for future research.
\end{abstract}

\title{
Keywords
}

co-benefits, community resilience, co-costs, resilience dividend, adaptation, mitigation 


\section{Acknowledgements}

The authors wish to thank all those who contributed ideas and suggestions for this report. Special appreciation is extended to David Butry (NIST); Harvey Cutler, Colorado State University; Maria Dillard (NIST); Kenneth Harrison (NIST); Edward Hanson (UMBC); Nicos Martys (NIST); Cheyney O’Fallon (NIST); and David Webb (NIST).

\section{Author Information}

Juan F. Fung

Economist

Applied Economics Office

Engineering Laboratory

National Institute of Standards and Technology

100 Bureau Drive, Mailstop 8603

Gaithersburg, MD 20899-8603

Tel.: 301-975-0484

Email: juan.fung@nist.gov

Jennifer F. Helgeson

Economist

Applied Economics Office

Engineering Laboratory

National Institute of Standards and Technology

100 Bureau Drive, Mailstop 8603

Gaithersburg, MD 20899-8603

Tel.: 301-975-6133

Email: jennifer.helgeson@nist.gov

\section{Disclaimers}

The policy of the National Institute of Standards and Technology is to use metric units in all of its published materials. Because this report is intended for an audience that often uses U.S. customary units, it is more practical and less confusing to include U.S. customary units as well as metric units. Measurement values in this report are therefore stated in metric units first, followed by the corresponding values in U.S. customary units within parentheses. 


\section{Table of Contents}

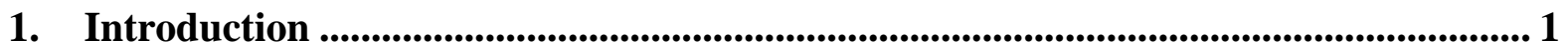

2. The resilience dividend arising from co-benefits of community resilience planning 3

2.1. Conceptual Background .............................................................................................. 4

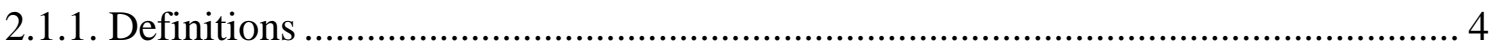

2.1.2. Co-benefits related to resilience ...................................................................... 7

2.1.3. Co-benefits of climate change and other objectives ............................................... 10

2.2. Methodological Contributions................................................................................. 11

2.2.1. Assessment methodologies................................................................................ 11

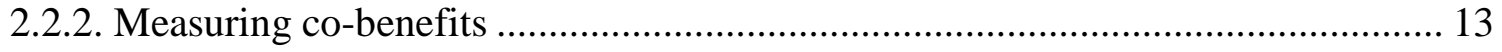

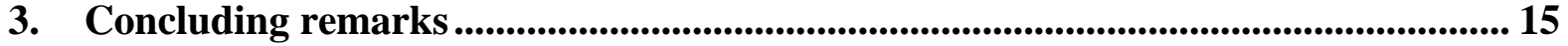

3.1. Potential approaches to quantifying the resilience dividend ......................................... 15

3.1.1. Computable general equilibrium (CGE) models .................................................. 16

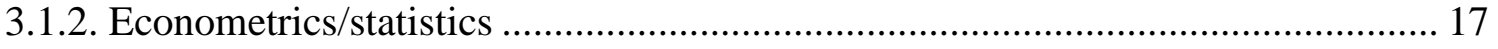

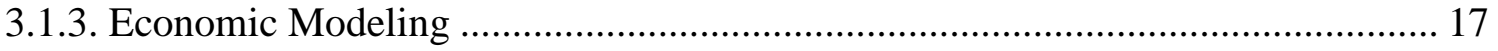

3.1.4. Field Studies ……………………………………........................................... 18

3.2 Concluding remarks ....................................................................................... 18

A. Appendix..................................................................................................................... 19

A.1. Annotated bibliography …………………………............................................ 19

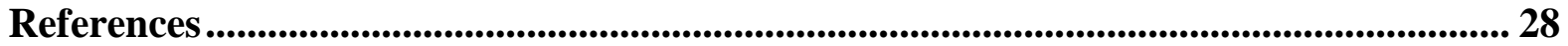




\section{List of Tables}

Table 1: Categorization of co-benefit definitions found within the reviewed literature.......... 6

Table 2: Examples of co-benefits and co-costs related to resilience investments ................... 7

Table 3: Co-benefits associated with non-resilience objectives ....................................... 10 


\section{List of Acronyms}

BCA benefit-cost analysis

CCD Climate Compatible Development

CEA cost-effectiveness analysis

CES Cultural Ecological Services

CGE computable general equilibrium

CPG Community Planning Guide

DRM disaster risk management

EDG Economic Decision Guide

GAO Government Accountability Office

GHG greenhouse gas(es)

HUD Housing and Urban Development

IPPC Intergovernmental Panel on Climate Change

MCA multiple criteria analysis

NIST National Institute of Standards and Technology

PPD Presidential Policy Directive

SRBA Sustainability and Resilience Benefits Assessment 


\section{Introduction}

Historically, resilience planning in the research areas of engineering and economics has largely dealt with analyses on the basis of single buildings or infrastructure projects. The NIST Community Resilience Planning Guide ("the Planning Guide”) encourages communities to fold the concept of resilience into other community goals and plans (e.g., community business plans and disaster preparedness plans) (NIST 2016). Assessing plans related to increasing resilience at the community scale, as opposed to the asset level, addresses the interconnectedness of the structural, social, and natural systems that underlie a community's functions. ${ }^{1}$ However, resource challenges can arise when planning for resilience at the community level if such projects compete with other capital and social investments. This is especially difficult if potential benefits (i.e., forgone losses) accrue only when a disruptive event occurs.

The National Research Council (2012) defines resilience as "the ability to prepare and plan for, absorb, recover from or more successfully adapt to actual or potential adverse events,” a consistent definition with U.S. government agency definitions (SDR 2005; DHS 2008; PPD8 2011). Presidential Policy Directive 8 (PPD-8 2011) defines resilience as "the ability to adapt to changing conditions and withstand and rapidly recover from disruption due to emergencies.” Presidential Policy Directive 21 (PPD-21 2013) on Critical Infrastructure Security and Resilience expanded the definition to include the "ability to prepare for and adapt to changing conditions and to withstand and recover rapidly from disruptions." Further it states, "resilience includes the ability to withstand and recover from deliberate attacks, accidents, or naturally occurring threats or incidents."

A critical part of improving community-level resilience is acknowledging and prioritizing actions or projects for the buildings and infrastructure systems that support important social functions. A given community may assess the hazards it most readily faces and in turn prepare, mitigate risk, and plan recovery narrowly tailored to this assessment. However, it is also important to assess community goals in a broader, perhaps hazard agnostic, setting, as well, and ensure that these goals are addressed while planning for increased resilience.

Guidance on improving community resilience in the built environment suggests addressing high-level performance goals for routine, design, and extreme events (NIST 2016). In addition to preparing for potential shocks, resilience planning can address long-term community goals for stressors in the community. Stressors are typically unrelated to shocks, and include things such as high crime rates, plummeting economic growth, unemployment, and poverty. Resilience actions may also provide improvements that benefit a community without addressing stressors. For instance, elevating and remodeling a bridge may enhance resilience to flooding without reducing commute times or traffic congestion, but the new design may provide increased aesthetic amenity to the community. There is anecdotal

\footnotetext{
${ }^{1}$ The term community can be defined in various ways on the local and national scales. This report considers communities to refer to "a place designated by geographical boundaries that function under the jurisdiction of a governance structure” (e.g., town, city, county) (NIST 2016).
} 
evidence of improvements in community budgets, economic diversification, and greater social and economic opportunities for residents from community resilience planning (Rodin 2014).

Communities evaluating investments aimed at improving their resilience face a tradeoff between short-term costs and benefits that may only be realized if a disturbance occurs during the planning horizon. Thus, traditional estimates of return-on-investment generally assume a hazard event occurs within the analysis time frame. Yet, as mentioned, even in the absence of a disruptive incident, resilience investments may produce returns that are valuable to the community in other ways. Resilience investment options that achieve the same primary goal may differ with respect to co-benefits. For instance, levees provide flood control, a benefit to the community only in the case of a flood. In contrast, green space in a floodplain can provide a valuable resource to the community (through areas for recreation and increased natural landscapes) in the absence of a flood, while also providing flood control in the event of a flood. Without careful consideration of co-benefits, a community cannot fully evaluate the tradeoffs.

This report defines the resilience dividend as the net benefit (or cost) that accrues, from investments aimed at increasing resilience, in the absence of a disruptive incident over the planning horizon. The essence of the concept is the notion that investments in financing and resourcing long-term resilience may yield short-term economic benefits. The purpose of articulating and measuring the resilience dividend is to make co-benefits of resilience planning tangible. In this way, decision makers are less likely to undervalue resilience-related investments. This may include assigning value and considering co-benefits such as increased jobs and enhanced reliability of an infrastructure system, which improve the community even in the absence of a disruptive incident.

The idea of emphasizing such often overlooked benefits, or co-benefits, is not new. Much of the existing literature on valuing co-benefits, however, focuses on environmental policy, with a particular emphasis on climate change policy (e.g., Ürge-Vorsatz et al. 2014; Markandya et al. 2004). Recently, the concept of a resilience dividend has been specifically promoted by Rodin (2014) and her work with the Rockefeller Foundation. The World Bank advocates a similar concept, coined the "triple dividend of resilience," with a particular focus on development under the tenets of disaster risk management (DRM) ${ }^{2}$ (Mechler et al. 2016; Tanner et al. 2015; Vorhies and Wilkinson 2016).

A common theme in the co-benefits literature is the need for a standard assessment methodology. The question remains-how should decision makers incorporate the potential co-benefits of an investment into their evaluations? At the heart of this question is the fundamental problem of quantifying co-benefits. While some co-benefits may not have an

\footnotetext{
${ }^{2}$ Disaster risk management is a concept advocated to allow for increased disaster risk reduction (DDR). This concept is advocated by the UN Office for Disaster Risk Reduction (UNISDR) and is defined as the "practice of reducing disaster risks through systematic efforts to analyze and reduce the causal factors of disasters. Reducing exposure to hazards, lessening vulnerability of people and property, wise management of land and the environment, and improving preparedness and early warning for adverse events are all examples of disaster risk reduction" (Sendai Framework 2015).
} 
associated economic value, the large majority do. ${ }^{3}$ Attempts to provide an assessment methodology often begin by critiquing benefit-cost analysis (BCA), but they rarely result in a clear, mathematically rigorous alternative. Two common alternatives include: (1) multiple criteria analysis (MCA), and (2) cost-effectiveness analysis (CEA). These are typically applied ad hoc, on a case-by-case basis. Furthermore, the larger question of what constitutes a co-benefit remains unanswered.

This report provides a review of the literature on the resilience dividend and co-benefits, and highlights promising directions for future research quantifying the resilience dividend. In particular, there is a need to provide a standard definition of the "resilience dividend" and to produce a transparent methodology for measuring co-benefits of planning for increased resilience in practice. The report presents a definition of the resilience dividend that should be useful for practitioners of resilience, and suggests ways to measure the resilience dividend as defined in this report.

\section{The resilience dividend arising from co-benefits of community resilience planning}

Conceptual discussions of what co-benefits are and why they matter dominate the literature related to the concept of the resilience dividend. In this area, the literature is concentrated around qualitative assessments through the use of illustrative case studies. The proportion of papers dedicated to the quantification of co-benefits is relatively small. This is understandable, as co-benefits may be intangible, hard to describe, or difficult to quantify. Moreover, the term co-benefit is not used consistently across the literature to classify the types of ancillary benefits (and costs) of policies and plans that fall under the umbrella of potential co-benefits of increased resilience.

The majority of the literature is case study-based, with the goal of demonstrating a gap in the scientific and policy literature and, perhaps, offering guidance on the path toward a consensus view of co-benefits. A key finding throughout the literature is that decision makers consistently undervalue DRM investments because they fail to account for co-benefits (e.g., Tanner et al. 2015). The lesson that emerges is that making co-benefits more salient to stakeholders may help communities make better informed resilience investment decisions. This necessitates assessment methodologies that can incorporate quantifiable values of cobenefits into the overall policy assessment.

Standard quantitative and qualitative measurement across co-benefits is the logical first step toward developing a useful assessment methodology. However, a precise definition of what is or is not a co-benefit of enhanced resilience should form the foundation from which standard measurements are developed. The resilience dividend presents a particular

\footnotetext{
${ }^{3}$ Non-market valuation methods can be used to determine economic values of benefits that do not have market prices. Revealed preference approaches rely on price signals of related goods. For example, the market price paid for homes with respect to distance from an airport reveals the willingness to pay for reduced air pollution, or less noise, from the airport. Stated preference approaches rely on responses to questions about preferences. For example, a survey asking participants to rank their favorite homes, differentiated by distance to an airport, may be used to infer preferences for noise pollution.
} 
challenge, since community resilience is a fairly new concept itself and a standard metric for resilience does not exist.

The next section presents a review of scientific and policy research on co-benefits, loosely categorized as either conceptual or methodological. Much of this work focuses on disturbances related to climate change. Case studies form a significant part of the research. While this list is comprehensive, it is by no means exhaustive.

\subsection{Conceptual Background}

A large proportion of the papers surveyed in this report are dedicated to developing the concept of co-benefits. This part of the literature focuses on defining co-benefits and explaining why they matter to investments aimed at increasing community resilience, climate change mitigation and adaptation, development, and other objectives. The definitions vary based on whether co-benefits are implicitly or explicitly pursued in the development of the plan or policy under consideration. Case studies form a significant part of this research, while other papers review the literature for a particular objective (e.g., policies targeting public health, agricultural biodiversity, and family planning in the developing world).

In her coining of the term "resilience dividend," Rodin (2014) notes that "resilience-building is also a lever for unlocking greater economic development and business investment, as well as improved social services and more broadly shared prosperity.” The series of case studies presented in Rodin (2014) center around a conceptual discussion of the resilience dividend having two potential components: (1) the difference between how a disruptive incident and the associated shock or stresses may affect a community that has made resilience-related investments compared to the counterfactual of the community not making such investments; and (2) co-benefits that investing in resilience can yield to a community, such as job creation, social cohesion, and equity. As articulated in the NIST Community Resilience Economic Decision Guide (EDG), the first element is traditionally included as part of a BCA, as avoided losses (Gilbert et al. 2016). The second is the focus of this paper.

\subsubsection{Definitions}

The resilience dividend, as defined in this report, is the net co-benefit (or co-cost) of resilience investments, in the absence of a disruptive incident over the planning horizon. ${ }^{4}$ While this definition appears straightforward, it masks the complexity that arises from the myriad of possibilities that the term "co-benefit" may convey. Examples of what are considered co-benefits of community resilience planning include:

- $\quad$ Enabling individuals, communities, and organizations to better withstand and recover from a disruption more quickly and effectively;

\footnotetext{
${ }^{4}$ Given the definition of the resilience dividend as a net co-benefit, references to co-costs are dropped in the remainder of the report with the understanding that the resilience dividend may be negative if co-benefits are negative (i.e., if co-costs outweigh co-benefits).
} 
- $\quad$ Reducing the impact of chronic stresses, such as crime, poverty, and unemployment, and improving a community's ability to maintain essential functions following a disturbance;

- Improving the community's attractiveness to residents and businesses by adding features and facilities and/or increasing the likelihood of continuity in the face of a disturbance.

In reviewing the literature, this report finds that definitions used to describe co-benefits tend to fall, loosely, into three classes. The purpose of this classification is to provide of a frame of reference for what may be considered a co-benefit, so that a city manager or resilience officer can decide what co-benefits are appropriate for their community. Note that these categories are distinct in nature, but are not mutually exclusive.

1. Objective-based definitions regard co-benefits as benefits to secondary objectives of a policy. For instance, Cedar Rapids, Iowa built an amphitheater along the west banks of the Cedar River that serves as a dual purpose facility providing both flood control and entertainment space. ${ }^{5}$ In this case, the primary objective was flood control, while secondary objectives included the local economy and recreation.

2. Intent-based definitions distinguish co-benefits as those benefits arising from deliberate planning. Thus, Cedar Rapids’ amphitheater provides co-benefits for the local economy by design. In contrast, if the city allows space to remain undeveloped, in order to mitigate flood risk, and this space naturally becomes a community space (e.g., a community garden), then any benefits beyond flood mitigation are not considered cobenefits as they were not deliberately planned for.

3. Finally, externality-based definitions treat co-benefits as synonymous with positive externalities: benefits to a party that is not part of a transaction. For instance, the community space in the previous example provides a positive externality to the community and is thus a co-benefit.

Intent-based and externality-based definitions seem antithetical. However, it is more instructive to view these classes as decreasing in generality. In particular, even deliberate targeting of secondary objectives may produce externalities. For instance, in the preceding examples, it is unclear whether each member of the community counts as a party to its community's investment in flood mitigation. If some sub-populations benefit more from a public space than others, is it the case that everyone bears the cost of the policy? This is likely to vary by community, across the spectrum of governance structures (e.g., village, township, city). Generally, co-benefits of resilience planning may accrue to first or third

\footnotetext{
${ }^{5}$ Information about the McGrath Amphitheater is available here: http://www.cedarrapids.org/discover_cedar_rapids/city_event_centers/mcgrath_amphitheatre.php
} 
parties to the investments. Yet, externalities are fundamentally defined by their associated costs (or benefits) accruing to third parties. ${ }^{6}$

Table 1, below, provides a classification of the co-benefit definitions noted in the reviewed literature.

Table 1: Categorization of co-benefit definitions found within the reviewed literature

\begin{tabular}{l|l|l|} 
Objective-based & Intent-based & Externality-based \\
\hline Mechler et al. (2016) & IPCC (2001) & Mechler et al. (2016) \\
\hline Tanner et al. (2015) & Mechler et al. (2016) & Herrero et al. (2013) \\
\hline Von Stechow et al. (2015) & Ürge-Vorsatz et al. (2014) & Markandya et al. (2004) \\
\hline $\begin{array}{l}\text { Vorhies and Wilkinson } \\
(2016)\end{array}$ & & Rose (2016) \\
\hline
\end{tabular}

Tanner et al. (2015) define co-benefits as the benefits for development or other objectives that arise in addition to the primary objective of reducing disaster risk. Vorhies and Wilkinson (2016) provide a similar definition. They define co-benefits as "benefits that accrue in addition to the primary DRM objectives of avoiding losses and boosting development.”

Similarly, Von Stechow et al. (2015) define co-benefits as "the potential positive effects of a policy aimed at one objective on other objectives, without evaluating social welfare implications."7 The paper draws from the integrated modeling work of the Working Group III Contribution to the Intergovernmental Panel on Climate Change (IPCC) Fifth Assessment Report (2014).

Ürge-Vorsatz et al. (2014) detail the variety of related terms in the literature and the confusion that arises due to imperfect overlap of these definitions (see their Figure 2). The key distinction is intent: does DRM planning specifically target other objectives? Thus, the authors define co-benefits as arising from intentionally pursuing multiple objectives.

The distinction drawn by Ürge-Vorsatz et al. (2014) is by no means standard. Markandya et al. (2004) treat co-benefits, ancillary benefits, and spillover effects as synonymous. Similarly, Herrero et al. (2013) treats co-benefits, ancillary benefits, and “forgotten benefits” as interchangeable. Rose (2016) defines co-benefits as "the broader benefits, or spillover effects, of DRM."

\footnotetext{
${ }^{6}$ Third parties used here as a generic term for any individual who does not have a direct connection with the resilience project (e.g., through financing or execution), but who might be affected by it.

${ }^{7}$ Formally, let $W(z, p)$ denote a social welfare function, where $z \in \mathbf{R}^{m}$ is a set of objectives and $p_{l} \in \mathbf{n}$ is a set of policies. If the net effect of $p$ on $W$ is

$$
d W=\sum_{i=1}^{m} \sum_{l=1}^{n} \frac{\partial W}{\partial z_{i}} \frac{\partial z_{i}}{\partial p_{l}}
$$

then the co-benefit of a policy $p_{l}$ on an objective $z_{i}$ is simply $\frac{\partial z_{i}}{\partial p_{l}}$.
} 
Nevertheless, Markandya et al. (2004) point out that the Intergovernmental Panel on Climate Change (IPCC) prefers the term co-benefits to reflect an integrated approach to valuation of these benefits (or costs) across climate change mitigation- and adaptation-related objectives and other objectives, such as development and public health; see IPCC (2001). ${ }^{8}$ Like ÜrgeVorsatz et al. (2014), the IPCC focuses on intent when classifying benefits as co-benefits

In contrast, Mechler et al. (2016) define co-benefits as "positive externalities that arise deliberately as a result of pursuing multiple objectives," drawing a distinction from ancillary benefits that arise without deliberate planning. This definition seems to draw upon aspects of each of the three classes: objective-based, intent-based, and externality-based.

Given the breadth of definitions surrounding co-benefits, the question remains: what is a standard definition of the resilience dividend that lends itself to quantifiable measurement and assessment? Clarifying the distinctions in definitions of co-benefits is more than a matter of semantics.

A precise definition is necessary for measurement and quantitative analysis. Defining the resilience dividend as the net benefits from investing in enhanced resilience in the absence of a disruptive event, as suggested in the introduction of this report, captures a community's intentional or unintentional pursuit of multiple objectives, and the possibility of creating externalities in the process. This distinction is important and distinguishes the resilience dividend as something tangible that may include co-benefits relative to a community's objectives, whatever those may be.

\subsubsection{Co-benefits related to resilience}

Table 2: Examples of co-benefits related to resilience investments

\begin{tabular}{lllll}
$\begin{array}{l}\text { Resilience } \\
\text { investment }\end{array}$ & Direct benefit & \multicolumn{2}{l}{ Co-benefit } & Relevant literature \\
\hline $\begin{array}{l}\text { Disaster Risk } \\
\text { Management }\end{array}$ & $\begin{array}{l}\text { Avoided or } \\
\text { reduced losses }\end{array}$ & $\begin{array}{l}\text { Economic resilience } \\
\text { and development (the } \\
\text { "Triple Dividend”) }\end{array}$ & $\begin{array}{l}\text { Tanner et al. (2015); } \\
\text { Vorhies and } \\
\text { Wilkinson (2016); } \\
\text { Mechler et al. (2016) }\end{array}$ \\
\hline $\begin{array}{l}\text { Small-business } \\
\text { initiatives (e.g., } \\
\text { long-term leases); } \\
\text { early warning } \\
\text { systems }\end{array}$ & $\begin{array}{l}\text { Tsunami } \\
\text { mitigation }\end{array}$ & $\begin{array}{l}\text { Resilient tourism } \\
\text { industry }\end{array}$ & Larsen et al. (2011) \\
\hline $\begin{array}{l}\text { Beach promenades; } \\
\text { elevated homes }\end{array}$ & $\begin{array}{l}\text { Tsunami } \\
\text { mitigation }\end{array}$ & $\begin{array}{l}\text { Tourism and fishing; } \\
\text { increased awareness } \\
\text { and preparedness }\end{array}$ & Khew et al. (2015) \\
\hline
\end{tabular}

${ }^{8}$ Markandya et al. (2004) also discuss ancillary costs. 


\begin{tabular}{l|l|l|l}
\hline Zoning changes & $\begin{array}{l}\text { Earthquake } \\
\text { mitigation }\end{array}$ & Sustainability & $\begin{array}{l}\text { Saunders and Becker } \\
(2015)\end{array}$ \\
\hline Green infrastructure & $\begin{array}{l}\text { Mitigate impacts } \\
\text { of heavy rainfall }\end{array}$ & Recreation & $\begin{array}{l}\text { Tomczyk et al. } \\
\text { (2016) }\end{array}$ \\
\hline Levees & Flood mitigation & $\begin{array}{l}\text { Overdevelopment in } \\
\text { floodplain }\end{array}$ & Wenger (2015) \\
\hline
\end{tabular}

The literature on co-benefits of resilience planning is small relative to that concerning cobenefits related to climate change and other environmental policies. This is unsurprising, as the concept of resilience planning is itself somewhat new and is largely concentrated in the development literature and is only now making its way into the discussion of resilience building in the developed world. Table 2 presents a classification of papers discussed in this section based on the identified co-benefits related to the resilience investment.

\subsubsection{The World Bank’s Triple Dividend}

A World Bank report presents the concept of the "Triple Dividend of Resilience" (Tanner et al. 2015), intended to capture the direct and indirect benefits of DRM with an emphasis on economic development. The three dividends are identified as: (1) avoided or reduced losses, in the event of a disruptive event occurring; (2) increased economic resilience, from reducing disaster risk; and (3) co-benefits for development. It is worth noting that boosting economic activity is a dividend in and of itself, while the co-benefits for development represent the third dividend.

The goal of the triple dividend is to increase investment in ex-ante DRM relative to the typical case of investing ex-post (i.e., following a disturbance). Tanner et al. (2015) argue that "existing methods of appraising investment decisions often fail to incentivize DRM because they undervalue the resulting benefit streams." This is a proposition developed in the series of World Bank working papers reviewed below.

Vorhies and Wilkinson (2016), for instance, discuss the limitations of using BCA to account for co-benefits and sketch out ways of incorporating co-benefits in analyses of potential DRM investments. The authors suggest adapting existing performance standards to include co-benefits, a task that may require developing a typology of co-benefits. Given the challenges in measuring co-benefits, a potential solution may be a hybrid method such as "qualitative BCA." 9

Another World Bank working paper focuses on the challenges in financing resilient DRM (Mechler et al. 2016). The main obstacle is budgeting for contingent liabilities such as disaster risk. The paper presents a review of policies in different countries and within the

\footnotetext{
${ }^{9}$ The idea behind qualitative BCA is to at least list potential benefits and costs, even in the absence of monetary value for each item.
} 
World Bank that attempt to reduce fiscal risk arising from inadequate disaster risk management. ${ }^{10}$

\subsubsection{Case studies}

Other papers present case studies on the co-benefits from a range of resilience investments.

Larsen et al. (2011) argue that tsunami mitigation efforts rarely address the social and economic impacts on communities. Their case study focuses on beach towns in Thailand. Recovery efforts in the case study sites often centered around tourism in both the short- and long-term, including financial assistance to businesses and a national marketing campaign for the tourism sector. Other initiatives included developing a tsunami early warning system and long-term leases to encourage business recovery (e.g., for tenant farmers). The authors point to a need for an analytical framework for comparing resilience policies that includes cobenefits for the community at large.

Khew et al. (2015) consider tsunami resilience in several towns in Chile and the co-benefits of two distinct actions: building a beach promenade and elevating homes. The authors find that beach promenades provide more co-benefits than elevating homes, though this may be a result of inadequate planning and design. More importantly, the authors find both actions yielded an additional co-benefit: residents perceived that the efforts increased tsunami awareness and preparedness.

Saunders and Becker (2015) argue that sustainability is necessary for resilience-otherwise, communities are doomed to repeated cycles of disturbance and recovery without at least reducing the intensity or magnitude of losses. They state the goal of resilience planning should be to build "even better" than before the disturbance in a way that yields benefits across "social, economic, cultural, and environmental” dimensions. To support this view, the authors present a case study of re-zoning with respect to seismic hazard in Christchurch, New Zealand.

Tomczyk et al. (2016) document the potential for green infrastructure to deliver resilience dividends. The authors present a case study of a national park in Poland. They find that trail design and maintenance provides direct benefits of mitigating the impacts of heavy rainfall (e.g., erosion) as well as indirect benefits (e.g., recreation).

Finally, Wenger (2015) presents an example of negative co-benefits (or co-costs). The author considers four case studies on the use of levees and dikes for flood control. The main finding is that levees result in a false sense of security in real estate, resulting in construction in floodplains and overdevelopment in hazardous areas. In other words, in terms of co-benefits there is little justification for extending levee efforts over pursuing alternatives (which may bring positive co-benefits that are not elaborated on in the paper).

\footnotetext{
10 For instance, Mexico’s FONDEN promotes “building back better” by providing innovative risk financing through catastrophe bonds and reinsurance. The World Bank itself developed a contingent credit instrument, the Catastrophe Drawdown Option (CAT DDO), which provides countries with a line of credit in case of disaster.
} 


\subsubsection{Co-benefits of climate change and other objectives}

Research on the co-benefits of climate change mitigation and adaptation is substantial and what follows by no means reflects the breadth and scope of that literature. Table 3 provides a classification of papers discussed in this section based on the identified direct benefit and cobenefit.

Table 3:Co-benefits associated with non-resilience objectives

\begin{tabular}{l|l|l} 
Direct benefit & Co-benefit & Relevant literature \\
\hline $\begin{array}{l}\text { Climate change mitigation } \\
\text { and adaptation }\end{array}$ & Economic development & $\begin{array}{l}\text { Mitchell et al. (2015); } \\
\text { Plaza-Bonilla et al. (2015); } \\
\text { Stern (2007); } \\
\text { Suckall et al. (2015) }\end{array}$ \\
\hline $\begin{array}{l}\text { Climate change mitigation } \\
\text { and adaptation }\end{array}$ & Resilience & GAO (2016); Gerber (2014) \\
\hline Public health & $\begin{array}{l}\text { Climate change mitigation } \\
\text { and adaptation }\end{array}$ & $\begin{array}{l}\text { De Souza (2015); } \\
\text { Machalaba et al. (2015) }\end{array}$ \\
\hline Agricultural biodiversity & $\begin{array}{l}\text { Food security; disease and } \\
\text { pest control }\end{array}$ & Frison et al. (2011) \\
\hline
\end{tabular}

Policies addressing climate change and development have been commonly presented as dual objectives (e.g., Stern 2007), situating them within the intent-based definition of co-benefits. Analogous to Tanner et al. (2015), Suckall et al. (2015) discuss the potential "triple wins" of climate policy: adaptation, mitigation, and development. The paper is a "meta-case study" of sorts, reviewing the empirical evidence for "triple wins" in Sub-Saharan Africa. The authors find that adaptation and mitigation projects often provide development co-benefits that go unrecognized.

Mitchell et al. (2015) define "climate-resilient development” as development that can handle climate-related shocks. The authors focus on land use planning and property rights as tools to address where urbanization occurs and secure land tenure. Thus, climate-resilient development is itself the co-benefit of urban planning.

Plaza-Bonilla et al. (2015) discuss the co-benefits of carbon sequestration for agriculture (e.g., crop productivity) and development (e.g., poverty alleviation) through a review of the literature. An important point they make is that the broader ecosystem services that carbon sequestration can provide should be mainstreamed into assessments to gain stakeholder support.

Recently, the intersection of climate change and resilience is receiving increased attention. A report by the Government Accountability Office (2016) reviews coordination, funding, and monitoring efforts in the US, EU, Mexico, the Netherlands, and the Philippines to align climate change adaptation with enhanced resilience. The GAO's primary concern is federal fiscal exposure to weather-related disasters, including flood and crop insurance and direct federal assistance. The report argues that targeting resilience more broadly can produce co- 
benefits for weather-related disasters, other hazards, and the economy. Some highlights in the US include funding efforts (e.g., HUD’s National Disaster Resilience Competition) and monitoring efforts (work to "identify existing federal programmatic data sources which could be used as future indicators or metrics of community resilience”).

Gerber (2014) also argues that policies addressing climate change and resilience should be aligned. The author focuses on the challenges in developing local and regional policy, making the case that pursuing climate change through complementary management strategies is itself the co-benefit: policy targeting multiple objectives is more likely to be supported.

There are cases when climate change is the secondary objective of planning. Machalaba et al. (2015) consider the potential co-benefits for public health professionals from engaging the climate change community. The authors argue that issues in public health have significant overlap with climate change. Pursuit of joint policies, from an interdisciplinary perspective, can produce results with much broader impact than pursuing each objective in isolation.

Beyond climate change-related policies and actions, co-benefits arise in some unexpected settings_-illustrating just how broadly co-benefits may reach. For example, De Souza (2015) discusses the co-benefits of contraception on development; in this context, resilience itself is a co-benefit of family planning. Frison et al. (2011) argue for the co-benefits of agricultural biodiversity, including a resilient food stock, food security, and mitigation of disease and pest control.

Even when focusing only on climate change mitigation and adaptation, the literature demonstrates a wide range of objectives and applications. It is worth noting that much of the existing literature is concerned with secondary objectives in the context of the developing world. The nascent literature on the resilience dividend stands out as being equally concerned with co-benefits from pursuing multiple objectives in the context of the developed world.

\subsection{Methodological Contributions}

Methodological contributions appear to fall into two groups. The first group focuses on approaches to incorporating co-benefits into assessments of DRM investments. In some cases, these assessment methodologies are extensions of BCA, while in other cases they offer alternative approaches to BCA. The second group of papers focuses on quantitative approaches to measuring co-benefits, either analytical or empirical.

\subsubsection{Assessment methodologies}

If co-benefits arise from targeting multiple objectives, then an assessment methodology that incorporates those objectives would be desirable. Multiple-criteria analysis (MCA) is a field of operations research that structures and solves decision problems with multiple, perhaps conflicting, objectives. The general idea is to decompose a complex problem into constituent objectives and evaluate each in turn, with each objective weighed differently. It, therefore, seems a natural candidate for a co-benefits-aware assessment methodology.

Multiple-criteria analysis, also known as multiple-criteria decision-making, is a framework for analyzing a problem that explicitly considers multiple goals. As such, it is agnostic about 
solution methods used. ${ }^{11}$ In practice, as discussed below, applications of MCA tend to be adhoc or lack transparency.

Wardekker et al. (2016) present a five-step assessment methodology for resilience, with a particular focus on climate change-related resilience planning. A key step is determining the "resilience principles" that will guide decisions. In other words, it is important to identify the multiple objectives of a policy and its potential co-benefits across those objectives. The authors argue that this is important for strengthening stakeholder support. The methodological contribution includes a five-step assessment, with step five being the application of MCA (or a decision maker's quantitative tool of choice). ${ }^{12}$ It is not clear that this methodology is replicable, as the five-step assessment provides broad guidelines rather than a concrete formulation, and the illustrative case studies are largely descriptive.

Scrieciu et al. (2014) provide a climate policy-oriented methodology. The main contribution, MCA4climate, ${ }^{13}$ is an application of MCA focused on addressing development-compatible climate policies. This is no small task, and the authors detail the essential criteria for the problem, including co-benefits. However, the methodology presented in the paper is descriptive and it is not obvious how one might generalize or standardize the approach. The only examples given in the paper are a thought experiment and a summary of two case studies in which MCA4climate was used (in Mexico and Peru).

Other papers present assessment methodologies that are not explicitly based on MCA. Butler et al. (2014) propose a methodology for decision-making they call "adaptation pathways" that enumerates a community's objectives and their interactions to encompass vulnerabilities beyond climate change. In doing so, the process should clarify a community's broader social objectives, as well as potential tensions from stakeholders. Like MCA, adaptation pathways explicitly consider multiple objectives, though on some level the goal is to determine the multiple objectives.

The aim of this approach is to provide a common framework for comparing alternative strategies that consider climate change adaptation in the broader social and economic context of resilience (e.g., poverty alleviation) and to account for the diverse, often conflicting, objectives of community stakeholders. The adaptation pathways approach seeks to draw attention to (rather than quantify) potential co-benefits for poverty alleviation, climate

\footnotetext{
${ }^{11}$ Multiple-objective optimization is a well-defined solution method that applies the structure of mathematical programming to a problem framed within an MCA. Intuitively, it is analogous to solving for the Pareto frontier.

12 The five steps may be summarized as: (1) characterize the system; (2) characterize objectives; (3) characterize available investments; (4) assess each investment's impact on resilience; and (5) "follow-up analysis," including quantitative assessment.

${ }^{13}$ The MCA4climate methodology is an initiative of the United Nations Environment Programme (UNEP). See http://www.mca4climate.info/ for more details. The framework is based on identifying potential co-benefits of climate policies (in particular, for development) and scoring alternative policies using MCA.
} 
adaptation, and greenhouse gas mitigation. ${ }^{14}$ As such, the methodology is highly qualitative. ${ }^{15}$

Grafakos et al. (2016) argue that sustainability and resilience are "two intertwined concepts." 16 The authors present an assessment methodology for resilience and sustainability. The Sustainability and Resilience Benefits Assessment (SRBA) methodology compares benefits of an investment relative to a status quo and thus bears a superficial resemblance to BCA. The key step is dividing benefits into four categories: environmental, social, economic, and institutional. ${ }^{17}$ The categorization aids in cataloging, and thus in quantifying, the numerous benefits accrued from a given mitigation strategy. The SRBA assessment methodology explicitly considers multiple objectives and potential benefits of a policy on those objectives.

Herrero et al. (2013) argue that standard BCA is limited to benefits and costs with market prices. They propose an extension, which they call 'social BCA,' that captures utility gains and losses. The idea is to include social welfare implications of policy in BCA. The authors evaluate energy efficiency retrofits in Hungary and show that such climate investments yield net positive benefits much sooner under social BCA than under standard BCA. This is because social BCA considers co-benefits for reducing fuel poverty, including reducing excess winter mortality and improving indoor comfort.

As the preceding discussion shows, a standard assessment methodology does not exist. Extensions of BCA seem most natural, if such extensions can accommodate benefits distributed across a community. MCA is a promising alternative, but much work remains to be done.

\subsubsection{Measuring co-benefits}

Relative to the conceptual work and the research on assessment methodologies, few papers attempt to quantify co-benefits. This is puzzling, since measurement would seem a prerequisite for an assessment methodology. However, this disparity highlights the inherent challenges in quantifying co-benefits.

Burtraw and Toman (2000) discuss the co-benefits of greenhouse gas (GHG) mitigation for reducing other air pollutants. The authors detail some of the challenges in quantifying cobenefits. A key insight is that policies targeting long-range objectives, like climate change

\footnotetext{
${ }^{14}$ See Figure 1 and Table 3 in Butler et al. (2014) for illustration of the application of adaptation pathways to the case study.

${ }^{15}$ To illustrate the approach, Butler et al. (2014) conduct a case study in eastern Indonesia and compare this implementation with a hypothetical application in Australia.

${ }^{16}$ See also Saunders and Becker (2015).

${ }^{17}$ The SRBA methodology shares some similarities to the NIST Planning Guide, in the sense that it provides a step-by-step approach to resilience planning (see Section 6), and aims to highlight the direct and indirect (cobenefits) of sustainability and resilience planning.
} 
mitigation, require careful comparison with a reasonable "baseline" scenario. For instance, what reduction in other air pollutants would be expected in the absence of climate policy? Defining a suitable baseline scenario for secondary objectives is not straightforward, especially when outcomes evolve along different time scales. Reductions in particulate matter, for example, may be observed sooner than reductions in GHGs. In their review of related literature, they find a range for average co-benefits between 2 USD and 86 USD per ton of carbon reduction. ${ }^{18}$

In this spirit, Markandya et al. (2004) introduce a highly stylized model of national output subject to reductions in both GHGs and other air pollutants. The idea is to estimate additional reductions in other air pollutants when GHG reductions are mandatory, relative to a baseline in which they are not. The authors calibrate their model to UK data and produce estimates of co-benefits under a variety of scenarios. They find that co-benefits: (1) account for a 3 to $6 \%$ additional reduction in other air pollutants, and (2) cover roughly $4 \%$ of GHG mitigation costs. This paper is unique in providing a modeling framework for measurement and suggests a more rigorous modeling approach to quantifying co-benefits may be worth pursuing. ${ }^{19}$

Ürge-Vorsatz et al. (2014) discuss challenges in quantifying co-benefits in the context of climate change mitigation. In addition to the usual challenges, such as how to monetize benefits and avoiding double counting, the authors make the point that both the overall (or net) impact and the distributional effects of policy matter in the valuation of co-benefits. Net benefits matter when assessing the overall effectiveness of mitigation, but distributional effects provide an idea of the winners and losers of policy and, in particular, of potential stakeholders whose support is necessary. The authors also present a taxonomy of climaterelated co-benefits, including physical and monetary indicators and methods for measurement. They also review quantitative assessments of co-benefits in the literature, and find that co-benefits account for 53 \% (e.g., from renewable wind farms) to 350 \% (e.g., from thermal insulation) of direct benefits.

Campbell et al. (2015) argue that urban green space provides social benefits beyond the intended physical mitigation benefits. The authors quantify those co-benefits that matter most, using post-Hurricane Sandy New York City as a case study. In particular, they combine interviews and surveys of park users and staff with observational field data to determine the value of a parkland revitalization strategy. ${ }^{20}$ The authors find that community members place positive value on social co-benefits such as recreation, social relations, and environmental engagement. For instance, 25 to $29 \%$ of observed park use was recreational (sports or walking), with $24 \%$ of interviewees stating that they visit a park for its amenities.

\footnotetext{
18 The average co-benefits are expressed in 1996 USD.

${ }^{19}$ For instance, a computable general equilibrium (CGE) model, which accounts for transactions among all sectors in an economy, could provide estimates of the distributional effects of a policy such as GHG mitigation. This is discussed in the concluding section of this report.

${ }^{20}$ See the NYC Special Initiative for Rebuilding and Resilience's website, http://www.nyc.gov/html/sirr/html/home/home.shtml, for more details.
} 
Moreover, a majority of respondents visit a park because of its proximity to their home, school, or workplace.

Campbell et al. (2015) claim that their method is scalable and replicable. However, given the enormous time and effort necessary to collect primary data, this may not be feasible for many communities. Nevertheless, the paper is unique in that its explicit aim is to produce a method for assessing the co-benefits of resilience.

\section{Concluding remarks}

In this report, a definition of the resilience dividend is presented as the net co-benefits of investment in community resilience, in the absence of a disruptive incident over the planning horizon. This definition captures the breadth of co-benefits associated with the multiple objectives communities may consider when evaluating resilience investments. Moreover, the definition expresses the resilience dividend in a simple, understandable metric: a single, monetarized value. ${ }^{21}$

\subsection{Potential approaches to quantifying the resilience dividend}

Given a precise definition, the next step is to quantify the resilience dividend. An exhaustive typology of co-benefits is perhaps unnecessary, but work toward cataloging co-benefits should inform measurement efforts. This definition is flexible enough that communities can decide upon those objectives that matter most to them, focusing on these without leaving out critical information, and safely ignore the rest. Importantly, this implies that assessment methodologies based on BCA should suffice for measuring the resilience dividend of an investment. On the other hand, depending on a community's objectives (and data availability), more rigorous methods may be appropriate.

In what follows, four approaches to determining the sources of co-benefits and their associated magnitudes are reviewed and compared, namely:

(1) Computable general equilibrium (CGE) modeling: a simulation method focused on the macro-economy;

(2) Econometrics and statistical analysis: empirical methods of analysis;

(3) Economic modeling: analytical methods of analysis; and

(4) Field studies: observational methods

CGE modeling and econometric/statistical analysis generally require a large amount of data. Accessing such data may be more or less arduous depending on characteristics of the community. Economic modeling typically informs the use of CGE modeling and econometrics; however, in the emerging area of co-benefit analysis there is a place for theoretical economic modeling to be strongly informed by real world data analysis. Field

\footnotetext{
${ }^{21}$ The need to address non-market valuation for contributing benefits and costs to the extent possible is acknowledged (e.g.,NIST 2016). It is also the case that constraints on social dimensions of resilience goals may not be monetized, in which case they can contribute to defining the goals and objectives, which in turn confine the set of possible plans assessed in a BCA (Gilbert et al. 2016).
} 
work and the collection of primary data is increasingly prominent in economic research, especially in behavioral economics. Use of this technique may prove useful in learning about pathways for co-benefits that are not apparent in datasets and garnering information about the relative importance of non-market contributors to co-benefits.

\subsubsection{Computable general equilibrium (CGE) models}

CGE models are a class of economic models that use actual economic data to simulate how an economy might react to changes in policy, technology, or other external factors (Dixon and Jorgenson 2013). CGE models can quantify the distributional impacts of policy changes and can thus be used to estimate the net-benefits of enacting policies or implementing built environment changes that support resilience objectives (as discussed in Markandya et al. (2004) and Ürge-Vorsatz et al. (2014)).

Through the use of CGE models based on case-study communities in the real world, it is possible to compare economic outcomes under resilience-related investments and counterfactual outcomes without such investments. ${ }^{22}$

There is much discussion within the realm of CGE modeling on inherent ${ }^{23}$ and adaptive resilience $^{24}$ (e.g., Rose and Krausmann 2013). Typically, CGE modeling of resilience investments focuses on reaction to a disturbance event and how resilience investments make a difference relative to the status quo during and in the immediate aftermath of the disruptive event. Rather than focusing on reaction to a disturbance, the resilience dividend could be measured by examining the stream of co-benefits that arise from resilience planning, as well as socio-economic benefits in the long-term, that are not dependent upon a disturbance.

The analysis scale of CGE models is the macroeconomic steady-state of a community, region, or sovereign state. By looking at changes in the macro level of supply (production) and demand in a community's economy, it is possible to gain insight into the distribution of co-benefits arising from resilience investments and their associated magnitudes.

CGE models rest upon strong assumptions about optimizing behavior, competitive markets, and flexible relative prices. Lack of data may limit econometric estimation of key supply and demand parameters that serve as inputs to the model. Moreover, there are potential consistency problems because the variables that change from one equilibrium solution to the next are not necessarily consistent with each other during the period of change. Finally, the

\footnotetext{
22 In the literature on climate change mitigation, CGE models have been used to estimate the co-benefits of climate policy (e.g., taxes or controls on $\mathrm{CO}_{2}$ emissions) for non-greenhouse gas emissions and associated health outcomes. Given the nature of climate change, the model scale is generally national or a multi-country region. See, for instance, Dessus and O’Connor (2003); and Lu and Stern (2016).

${ }^{23}$ Inherent resilience being the ability to be resilient under normal circumstances (e.g., ability of markets to reallocate resources in response to price signals; e.g., Rose 2007).

${ }^{24}$ Adaptive resilience being the ability to be resilient in crisis situations (e.g., increasing input substitution possibilities in individual business operations; Rose 2007)
} 
fact that CGE models do not capture temporal scales can be a limiting factor in modeling resilience.

\subsubsection{Econometrics/statistics}

Econometric and statistical analyses based on real-world data are useful in establishing correlations and, potentially, causal effects related to recovery from a disturbance and resilience planning. In particular, causal inference (or policy evaluation in the economics literature) can be used to evaluate the direct or indirect impacts of policy aimed at enhancing resilience, by estimating economic outcomes relative to the counterfactual without such investments.

Beyond causal inference, data mining and machine learning methods could be used to infer patterns from data on communities. In turn, these may shed light on what makes some communities more resilient than others, and in turn, aid in comparing alternative approaches to enhancing resilience and their relative values.

A key technical advantage of statistical approaches relative to CGE modeling is the ability to quantify uncertainty, in terms of standard errors or confidence intervals. Surprisingly, there is little empirical work on quantifying co-benefits. This may be due to data limitations: while CGE models are data-intensive, they rely largely on aggregate data. Statistical approaches, and causal inference in particular, require data at a finer scale or simply more data (in terms of number of observations and number of predictors).

\subsubsection{Economic Modeling}

In the absence of data, analytical economic models can be invaluable in providing insights into the value of investing in resilience. A key advantage of analytical models is their level of abstraction: models can focus on the essential elements of a problem without getting mired in details. Theoretical results are often precise, general statements about what can or cannot happen under certain conditions, or they may illustrate gaps in understanding.

As an example, Von Stechow et al. (2015)'s definition of co-benefits, as the marginal impact of a policy $l$ on an objective $i$, can be embedded in a larger model in which a social planner chooses the best set of policies by maximizing social welfare, subject to constraints such as the marginal impact of policy $l$ on objective $i$ being non-negative. Depending on how policies are modeled and objectives defined, this simple optimization problem may reveal what is or is not feasible in the pursuit of enhanced resilience.

As another example, consider the variety of financing options for community investments in resilience, including debt issuance. Such financing structures could be used to quantify the return on investing in resilience in an asset pricing model. ${ }^{25}$

\footnotetext{
${ }^{25}$ One practical example of this is the D.C. Water and Sewer Authority's Environmental Impact Bond, issued in September, 2016. Sale proceeds fund green infrastructure to reduce combined sewer outflow during heavy
} 
Analytical models are often used to guide simulation-based methods. For example, the equations underlying CGE models are rooted in an analytical model of an economy. Moreover, such models can form the basis of econometric analysis. Asset pricing models are the workhorse of macroeconometrics and empirical finance (Campbell 2014). It is possible to imagine an econometric model based on Von Stechow et al. (2015)'s definition of marginal welfare with respect to multiple objectives and policies. Economic modeling can provide the foundation for rigorous, data-driven approaches and help articulate testable hypotheses around the resilience dividend.

\subsubsection{Field Studies}

Field studies allow collection of primary data. Such information can aid estimation of direct economic benefits related to costs-avoided (when a disruption occurs) in the medium- and long-terms and socio-economic benefits over time that are not dependent upon the occurrence of disruptive event. For example, stated preference evaluation of willingness-topay or willingness-to-accept of members of the local community during a field study may provide valuation information related to social functions that may not be otherwise available. When considering pathways for co-benefits, it is likely that using more social data will yield better understanding and potentially allow for more precise sensitivity analyses.

Of course, field studies are costly, time-consuming, and labor intensive. Thus, field work for the purpose of collecting primary data on co-benefits may not be a viable option for most researchers or policy makers.

\subsection{Concluding remarks}

Enhancing community resilience is not trivial and communities do not face a binary choice between being resilient or not. The range of options varies by community. It is therefore important that communities are aware of the multiple objectives that matter most to them, which may include enhanced resilience. The concept of the resilience dividend helps communities compare investment options using a metric that encompasses multiple objectives and recognizes strengthening the community in the day-to-day, even when a hazard event has not occurred. The purpose of this review is to assist researchers and the policy community as they look toward making a "business case" for resilience.

storms. For more details, see: http://www.goldmansachs.com/media-relations/press-releases/current/dc-waterenvironmental-impact-bond-fact-sheet.pdf. 


\section{A. Appendix}

\section{A.1. Annotated bibliography}

This section presents an annotated bibliography of the papers surveyed to develop this report. The goal of the annotations is to provide a quick reference for both practitioners and researchers looking for more in-depth analysis of co-benefits and community resilience.

Burtraw, D. and Toman, M., 2000. “Ancillary Benefits” of Greenhouse Gas Mitigation Policies. Climate Change Economics and Policy: An RFF Anthology.

This paper discusses the challenges in quantifying co-benefits of greenhouse gas (GHG) mitigation. The authors define ancillary benefits, or co-benefits, as benefits that accrue in addition to benefits for the primary objective of climate change mitigation. The challenges identified include: (1) defining the baseline scenario; (2) defining the counterfactual scenario in which GHG mitigation policy is implemented; (3) defining the scale of the analysis, as well as the scope of the policy; and (4) inherent difficulties in defining and measuring specified benefits (e.g., improvements in health from reduced air pollution). To illustrate, the authors provide a brief literature review on empirical estimates of the co-benefits from climate change mitigation for reducing $\mathrm{SO}_{2}$ and $\mathrm{NO}_{\mathrm{x}}$ emissions.

Butler, J.R.A. et al., 2014. Framing the application of adaptation pathways for rural livelihoods and global change in eastern Indonesian islands. Global Environmental Change, 28, pp.368-382. Available at: http://dx.doi.org/10.1016/j.gloenvcha.2013.12.004.

This paper presents an assessment methodology for climate change planning, which the authors call "adaptation pathways." The main argument is that climate change adaptation should also address broader resilience, in particular "human development," to generate co-benefits for communities and in particular the rural poor. The proposed methodology aims to place climate change planning within this larger context by carefully articulating a community's diverse objectives.

To illustrate the approach, Butler et al. (2014) conduct a case study in the eastern Indonesian province of Nusa Tenggara Barat and compare implementation with a hypothetical application in Australia. The biggest difference between the two cases is the relative standards of living. A more developed country like Australia is likely to have a different objective, with a lower opportunity cost to "mis-adaptation" and a different (i.e., industrial rather than agricultural) stakeholder base.

Campbell, L.K. et al., 2015. A social assessment of urban parkland: Analyzing park use and meaning to inform management and resilience planning. Environmental Science and Policy, 62, pp.34-44. Available at: http://dx.doi.org/10.1016/j.envsci.2016.01.014. 
The main contribution of this paper is a method for quantifying "Cultural Ecosystem Services" (CES), ${ }^{26}$ i.e., co-benefits, of urban green space. This paper is unique in its attempt to measure the co-benefits of a particular resilience strategy. The authors illustrate their methodology with a case study of the Jamaica Bay in New York City and its response to 2012's Hurricane Sandy.

De Souza, R.-M., 2015. A Little Bit of Sugar Helps the Pill Go Down: Resilience, Peace, and Family Planning Comment on "The Pill Is Mightier Than the Sword”. International Journal of Health Policy and Management, 5(2), pp.113-116. Available at: http://dx.doi.org/10.15171/ijhpm.2015.175.

This paper is a comment on an article (Potts et al. 2015) arguing that contraception is crucial to peacebuilding. The commentary goes further, arguing that a "business case" must be made for contraception interventions to succeed. The business case comes down to articulating the co-benefits from such efforts: economic productivity, community building, conservation, resilience, and, of course, peacebuilding. It is worth noting that the author thinks of resilience itself as a co-benefit of family planning. The author connects his argument with the World Bank/ODI's concept of "triple dividends" (Tanner et al. 2015).

Frison, E.A., Cherfas, J. and Hodgkin, T., 2011. Agricultural biodiversity is essential for a sustainable improvement in food and nutrition security. Sustainability, 3(1), pp.238-253.

The authors argue that agricultural biodiversity is critical to food security. The main point is that biodiversity provides direct and indirect benefits, including a resilient stock. Direct benefits are increased food productivity. Indirect benefits are underappreciated, and include food security, mitigation of disease and pest control, and increased human productivity through improvements in nutrition. The authors make their case by citing existing literature, contextualizing a diverse body of work under the broad umbrella of sustainability through agricultural biodiversity.

Gerber, B.J., 2014. Climate Change as a Policy Development and Public Management Challenge: An Introduction to Key Themes. Risk, Hazards \& Crisis in Public Policy, 5(2), pp.97-108.

This paper, which serves as an introduction to a special issue of Risk, Hazards \& Crisis in Public Policy, focuses on the policy challenges facing local, national, and global governance. Climate change adaptation and mitigation policy requires cooperation among the public and private sectors, and across jurisdictions. The author argues that careful climate change planning can yield a co-benefit of simultaneously addressing mitigation, adaptation, and resilience.

\footnotetext{
${ }^{26}$ The concept of CES is borrowed from the Millennium Ecosystem Assessment(2005), which defines CES as "non-material benefits people obtain from ecosystems through spiritual enrichment, cognitive development, reflection, recreation, and aesthetic experiences."
} 
Government Accountability Office, 2016. Climate Change: Selected Governments Have Approached Adaptation through Laws and Long-Term Plans.

This report focuses on "resilience through climate change adaptation" and "aligned adaptation with broader resilience efforts:” steps the US and other countries are taking to become resilient to climate change risks, as well as efforts that target resilience more broadly. Highlighted efforts in the US and other countries include legislation and long-term plans; coordination mechanisms such as Climate-ADAPT in the EU; funding efforts (primarily FEMA and HUD in the US); and monitoring (measurement) efforts. Table 3, Appendix I, lists relevant US efforts, in reverse chronological order.

Grafakos, S., Gianoli, A. and Tsatsou, A., 2016. Towards the Development of an Integrated Sustainability and Resilience Benefits Assessment Framework of Urban Green Growth Interventions. Sustainability, 8(461), pp.1-33.

The goal of this paper is to provide a methodology for assessing the benefits of sustainable urban planning and development. In particular, they point to Cali, Colombia as a city with whom they implemented an urban green growth strategy (enhancing an urban forest). The proposed assessment framework, "Sustainability and Resilience Benefits Assessment” (SRBA), incorporates an inventory of four classes of co-benefits (environmental, social, economic, and institutional) with GIS analysis to map the distribution of benefits across a community. In a nutshell, the SRBA methodology is as follows:

1. Identify project and main components

2. Identify expected benefits

3. Develop indicators for expected benefits to quantify impacts

4. Develop baseline (status quo)

5. Develop project scenario

6. Estimate change relative to baseline

7. Tabulate benefits across impact level (individual, neighborhood, city, global) in the SRBA Matrix.

Herrero, S.T., Ürge-Vorsat, D. and Petrichenko, K., 2013. Fuel poverty alleviation as a cobenefit of climate investments: evidence from Hungary. In European council for an energy efficient economy summer study. pp. 1605-1616.

The authors argue that climate change mitigation efforts can have co-benefits for fuel (energy) poverty. To make their case, the authors introduce "Social cost-benefit analysis” (social BCA) and compare this to standard BCA, applied to hypothetical 
energy efficiency investments in Hungary. Their results show that this particular greenhouse gas mitigation policy yields co-benefits of reducing fuel poverty mortality, improving comfort, reducing other pollutants.

Khew, Y.T.J. et al., 2015. Assessment of social perception on the contribution of hardinfrastructure for tsunami mitigation to coastal community resilience after the 2010 tsunami: Greater Concepcion area, Chile. International Journal of Disaster Risk Reduction, 13, pp.324-333. Available at: http://dx.doi.org/10.1016/j.ijdrr.2015.07.013.

This paper focuses on multifunctional resilience, a concept originating in ecology. Multifunctionality captures the idea of co-benefits: direct mitigation and indirect social/economic benefits. The authors use the Concepcion region in Chile to illustrate two particular "hard-infrastructure" efforts aimed at tsunami resilience: beach promenades and elevated houses. The authors interviewed residents in some of the towns affected by a 2010 tsunami about their town's response. ${ }^{27}$ Residents found that beach promenades provided a net positive economic benefits, by boosting tourism and fishing, while elevated houses provided net negative benefit, based on inadequate design and cutting families off from each other.

Larsen, R.K., Calgaro, E. and Thomalla, F., 2011. Governing resilience building in Thailand's tourism-dependent coastal communities: Conceptualising stakeholder agency in social - ecological systems. Global Environmental Change, 21(2), pp.481-491. Available at: http://dx.doi.org/10.1016/j.gloenvcha.2010.12.009.

The authors argue for a "systems perspective" toward resilience that accounts for stakeholder agency to support DRM, the stakeholders being the community at large. The authors present a case study of popular beach destinations in Thailand's Andaman Coast that incurred major economic losses stemming from injuries and fatalities to both locals and tourists, in addition to infrastructure damage, following a 2004 tsunami. The main lesson from the case study is a methodology for comparing mitigation strategies that highlights potential co-benefits of action is needed. The authors provide such a framework, largely qualitative (see their Box 1, page 489), but stop short of addressing the larger question of how to quantify co-benefits.

Machalaba, C. et al., 2015. Climate Change and Health: Transcending Silos to Find Solutions. Annals of Global Health, 81(3), pp.445-458. Available at: http://dx.doi.org/10.1016/j.aogh.2015.08.002.

The paper makes the case to health professionals that reaching out to a broader set of collaborators and consumers can strengthen health initiatives, particularly in cases where climate change will affect health outcomes. Collaboration can target climate change "upstream” (causes) or "downstream" (effects). Alternatively, health practices can have climate effects (e.g., carbon footprints). The paper's contribution is mainly

\footnotetext{
${ }^{27}$ The towns are Coliumo, Dichato, Penco, Talcahuano, and Tumbes. Promenades were constructed in Dichato, Coliumo, and Penco, while elevated housing was constructed in Dichato, Coliumo, Talcahuano, and Tumbes.
} 
the sense that co-benefits are the shared gains from interdisciplinary/inter-sectoral initiatives ("co-investments"); see their Table 1. The authors identify opportunities for climate change-health collaboration based on a literature review.

\section{Markandya, A., Rübbelke, D.T.G. and Lavoro, N.D.I., 2004. Ancillary Benefits of Climate Policy. Journal of Economics and Statistics/Jahrbücher für Nationalökonomie und Statistik, 224(4), pp.448-503.}

The authors discuss the importance of co-benefits (or “ancillary benefits”) for climate policy, as well as the main differences between primary benefits and secondary benefits. In the context of climate policy, the main difference is that co-benefits are often realized sooner than primary, climate change benefits. The authors review papers attempting to quantify co-benefits of climate policy, demonstrating a range of methods and estimates. The main contribution is a model that is calibrated to UK gross domestic product (GDP) data. Using this model, the authors find that greenhouse gas mitigation has positive co-benefits for air pollution: additional reductions in air pollution can cover about $4 \%$ of greenhouse gas mitigation.

Mechler, R., Mochizuki, J. and Hochrainer-Stigler, S., 2016. Disaster Risk Management and Fiscal Policy: Narratives, Tools, and Evidence Associated with Assessing Fiscal Risk and Building Resilience., p.39.

The main question studied in the paper is whether and how fiscal policy can incorporate co-benefits of DRM. In particular, the authors note that fiscal budgeting focuses on direct liabilities, whereas disaster risks arise as contingent liabilities. By framing DRM within fiscal risk, the authors highlight the necessary steps for mainstreaming DRM and, consequently, financing resilience. The idea is to gradually develop a disaster planning framework that deliberately targets co-benefits. Methodological suggestions for fiscal policy evaluation include cost-benefit analysis, cost-effectiveness analysis, and multiple criteria analysis.

Mitchell, D., Enemark, S. and Molen, P.V.D., 2015. Climate resilient urban development: Why responsible land governance is important. Land Use Policy, 48, pp.190-198.

The paper argues that urban planning should align with broader climate resilience. ${ }^{28}$ In developing countries, urbanization in hazardous areas, often un-zoned and illegally occupied, is common and creates communities that are especially vulnerable to climate-related risks. The main tools the authors discuss, through a review of the literature, are land use planning, to address where development occurs, and property rights, to address land tenure. ${ }^{29}$

\footnotetext{
${ }^{28}$ In this context, resilience indicates climate change mitigation and adaptation specifically.

29 The idea that land use planning in particular can have important co-benefits for DRM is also addressed in Saunders and Becker (2015).
} 
Plaza-Bonilla, D. et al., 2015. Carbon management in dryland agricultural systems. A review. Agronomy for Sustainable Development, 35, pp.1319-1334.

This article highlights the potential co-benefits of carbon sequestration programs in dryland agricultural areas. The stated objective of sequestration is to reduce atmmospheric $\mathrm{CO} 2$ and thus to mitigate climate change. The indirect benefits (or cobenefits) include: crop productivity, sustainable agriculture, environmental restoration, and poverty alleviation. The language used treats co-benefits and positive externalities as interchangeable.

Rodin, J., 2014. The Resilience Dividend: Being Strong in a World Where Things Go Wrong, Public Affairs.

This book presents a number of examples of the resilience dividend worldwide. The book argues that resilience can be improved at the community scale not through only infrastructure, but also through social relationships. She highlights four key issues that makes resilience planning more important than in the past: (1) the rate at which change is occurring; (2) globalization; (3) immense scale of urbanization worldwide; and (4) climate change. Yet, there is an unprecedented ability to deploy new technologies and data systems to better assess and understand threats, analyze populations that will be most impacted by those threats, provide information feedback loops that allow for rapid decision-making and change even during shocks, and build strategies that allow for quicker and safe rebounds following a hazard event. The argument is that there is a dividend inherent in planning for greater resilience because many solutions also entail increased economic development and business investment, as well as improved social services.

Rose, A., 2016. Capturing the Co-Benefits of Disaster Risk Management on the Private Sector Side.

This paper considers private sector investment in disaster risk management (DRM) and the role of co-benefits in helping firms make investment decisions. In particular, the author focuses on resilience investments that reduce losses from business interruption.

Saunders, W.S.A. and Becker, J.S., 2015. A discussion of resilience and sustainability: Land use planning recovery from the Canterbury earthquake sequence, New Zealand. International Journal of Disaster Risk Reduction, 14, pp.73-81. Available at:

http://dx.doi.org/10.1016/j.ijdrr.2015.01.013.

The authors ask two important questions: (1) what does resilience mean, and (2) what is the relationship between resilience and sustainability? ${ }^{30}$ To answer these questions, the authors present a case study based on the magnitude 7.1 Darfield earthquake of September 4, 2010, and its impact on the city of Christchurch, New Zealand. The

30 See also Grafakos et al. (2016) 
Christchurch earthquake, a 6.3 magnitude aftershock from Darfield, hit the city on February 22, 2011, derailing recovery efforts related to the first quake.

This case study illustrates not only resilience planning in a particular context, but also supports the authors' view that sustainability is necessary for resilience planning. The authors view co-benefits in the context of ensuring a community's future well-being, and hence, as making it more sustainable. To this end, Christchurch adopted a rezoning strategy that accounted for seismic hazard, in contrast to previous short-term recovery efforts such as re-building with respect to the status quo (the key element was "red-zoning" land vulnerable to liquefaction).

Scrieciu, S.Ş. et al., 2014. Advancing methodological thinking and practice for developmentcompatible climate policy planning. Mitigation and Adaptation Strategies for Global Change, 19(3), pp.261-288.

The main contribution is an assessment methodology, MCA4climate, an application of MCA for the evaluation of climate-compatible development. ${ }^{31}$ The paper sets out an ambitious agenda: "a new methodological approach to address [the] deficiencies" in standard economic analysis. In particular, the authors criticize general equilibrium, for being overly focused on optimality, and BCA, for its limitations in dealing with dynamics, uncertainty, and non-market goods. Absent is a formal comparison between standard BCA and the methodology presented. Moreover, the concept of cobenefits forms the subtext of some of the discussion but is never formally discussed.

Suckall, N., Stringer, L.C. and Tompkins, E.L., 2015. Presenting Triple-Wins? Assessing Projects That Deliver Adaptation, Mitigation and Development Co-benefits in Rural SubSaharan Africa. AMBIO, 44(1), pp.34-41.

This paper argues for the "triple wins" of aligning development with broader climate change objectives: adaptation, mitigation, development co-benefits. The authors argue that adaptation and mitigation are necessary for development, but that development co-benefits are often underreported or ignored in the literature. The paper reviews case studies in Sub-Saharan Africa for evidence on potential "triple wins" of Climate Compatible Development (CCD). The authors identify a practical need for highlighting (if not quantifying) triple wins that is going unfulfilled in the academic literature: "robust criteria to evaluate triple wins do not exist." Closing this gap can have a significant impact on funding, investment, and participation.

Tanner, T. et al., 2015. The Triple Dividend of Resilience: Realising development goals through the multiple benefits of disaster risk management, Overseas Development Institute, The World Bank.

\footnotetext{
${ }^{31}$ MCA4climate is an initiative of the United Nations Environment Programme (UNEP) and appears to provide guidelines rather than a truly quantitative method; see http://www.mca4climate.info/.
} 
This report presents the concept of the "Triple Dividend of Resilience," developed in a series of World Bank working papers (Mechler et al. 2016; Rose 2016; Vorhies and Wilkinson 2016). Triple Dividends articulate all benefits of resilience planning to assist stakeholders in evaluating investment. The report focuses on development, as reflected in the three dividends: (1) loss avoidance; (2) economic resilience; and (3) co-benefits for development.

Tomczyk, A.M., White, P.C.L. and Ewertowski, M.W., 2016. Effects of extreme natural events on the provision of ecosystem services in a mountain environment: The importance of trail design in delivering system resilience and ecosystem service co-benefits. Journal of Environmental Management, 166, pp.156-167. Available at: http://dx.doi.org/10.1016/j.jenvman.2015.10.016.

The authors present a case study on the co-benefits of green infrastructure such as park trails. In particular, they collected data on the number of visits to Gorce National Park in Poland, before and after a period of intense rainfall in May, 2010. In addition, they collected field data on the trails following the event, which they compared to pre-event information from the park. They found declines in both the number of visits and in two ecosystem services: erosion prevention and biodiversity. Moreover, recovery sometimes took years, depending on pre-event trail maintenance (or lack thereof).

Ürge-Vorsatz, D. et al., 2014. Measuring the Co-Benefits of Climate Change Mitigation. Annual Review of Environment and Resources, 39(October), pp.549-582.

This paper provides a thorough review of co-benefits associated with climate change mitigation policy. The authors present a detailed conceptual discussion of co-benefits, including the variety of definitions in the literature. They also discuss the importance of having a taxonomy of "co-impacts" (co-benefits and co-costs) and the difficulties associated in identifying potential co-benefits. Key issues in quantifying co-benefits are also discussed, including how to monetize benefits and double counting. Finally, the authors also discuss three potential assessment methodologies: "social" BCA (as in Herrero et al. (2013), discussed above); integrated assessment modeling; and MCA.

Von Stechow, C. et al., 2015. Integrating Global Climate Change Mitigation Goals with Other Sustainability Objectives: A Synthesis. Annual Review of Environment and Resources, 40, pp.363-394.

This paper explicitly reviews the literature on co-benefits of climate change planning in the social dimension. The main insight is that the value of co-benefits remains unquantified. The authors argue that climate change mitigation policy requires targeting multiple (non-climate) objectives, such as human health and energy security, simultaneously rather than separately. This is because targeting one objective can produce co-benefits for other, overlapping objectives. Moreover, this requires policy at all levels of governance. The main objective is to synthesize the 
broad and disparate literature on co-benefits. One observation they note is that the definition of co-benefits is not standardized, with a wide range of uses in different contexts.

Vorhies, F. and Wilkinson, E., 2016. Co-Benefits of Disaster Risk Management.

The authors argue that failure to account for co-benefits results in underinvestment in DRM. The paper discusses the challenges in capturing co-benefits within traditional BCA: (1) co-benefits are often intangible and difficult to value; (2) co-benefits often accrue beyond the life of a project and thus may be heavily discounted in present value calculations; (3) hazard uncertainty and time-sensitive decisions may lead to missed opportunities to capture co-benefits; and most importantly, (4) aggregation of benefits in BCA masks the distributional impacts of DRM investments. The latter point is important in making a business case for resilience investments, since cobenefits are unevenly distributed across stakeholders.

Wardekker, J.A. et al., 2016. Screening regional management options for their impact on climate resilience: an approach and case study in the Venen-Vechtstreek wetlands in the Netherlands. SpringerPlus, 5(1), pp.1-17.

This paper provides a five-step assessment method for comparing resilience strategies. A key step is assessment of resilience based on pre-determined ecological criteria (what the authors dub "resilience principles”), which should point out cobenefits of mitigation efforts. The authors apply their method to resilience planning in the Dutch Groot Wilnis-Vinkeveen wetland area of the Venen-Vechtstreek region, incorporating $\mathrm{MCA}^{32}$ in step 5 of the case study analysis. The latter revealed the importance of co-benefits, though without directly quantifying them. ${ }^{33}$

Wenger, C., 2015. Better use and management of levees: reducing flood risk in a changing climate. Environmental Reviews, 23(2), pp.240-255.

To levee, or not to levee? That is the question addressed in this paper. The authors apply cost-benefit analysis to four case studies in the US, Australia, China, and the Netherlands. Central to this analysis is the idea that levees and dikes must stand up to alternatives (such as ecosystem-based measures of flood risk mitigation) in terms of co-benefits. Levees lead to overdevelopment in hazardous areas, a negative cobenefit. The paper presents a great example of a negative case for a disaster risk management tool, due in part to the lack of positive co-benefits.

\footnotetext{
32 See also Scrieciu et al. (2014).

33 Table 1 lists mitigation options considered for the case study, including co-benefits. For instance, balanced fertilization has the potential for cleaner water and increased biodiversity.
} 


\section{References}

Burtraw, D. and Toman, M., 2000. “Ancillary Benefits” of Greenhouse Gas Mitigation Policies. Climate Change Economics and Policy: An RFF Anthology.

Butler, J.R.A. et al., 2014. Framing the application of adaptation pathways for rural livelihoods and global change in eastern Indonesian islands. Global Environmental Change, 28, pp.368-382. Available at: http://dx.doi.org/10.1016/j.gloenvcha.2013.12.004.

Campbell, J.Y., 2014. Empirical Asset Pricing: Eugene Fama, Lars Peter Hansen, and Robert Shiller. The Scandinavian Journal of Economics, 116(3), pp.593-634.

Campbell, L.K. et al., 2015. A social assessment of urban parkland: Analyzing park use and meaning to inform management and resilience planning. Environmental Science and Policy, 62, pp.34-44. Available at: http://dx.doi.org/10.1016/j.envsci.2016.01.014.

De Souza, R.-M., 2015. A Little Bit of Sugar Helps the Pill Go Down: Resilience, Peace, and Family Planning Comment on “The Pill Is Mightier Than the Sword”. International Journal of Health Policy and Management, 5(2), pp.113-116. Available at:

http://dx.doi.org/10.15171/ijhpm.2015.175.

Dessus, S. and O’Connor, D., 2003. Climate policy without tears: CGE-based ancillary benefits estimates for Chile. Environmental and Resource Economics, 25(3), pp.287-317. Available at: http://dx.doi.org/10.1023/A:1024469430532.

DHS, 2008. DHS Risk Lexicon.

Frison, E.A., Cherfas, J. and Hodgkin, T., 2011. Agricultural biodiversity is essential for a sustainable improvement in food and nutrition security. Sustainability, 3(1), pp.238-253.

Gerber, B.J., 2014. Climate Change as a Policy Development and Public Management Challenge: An Introduction to Key Themes. Risk, Hazards \& Crisis in Public Policy, 5(2), pp.97-108.

Gilbert, S.W. et al., 2016. Community Resilience Economic Decision Guide for Buildings and Infrastructure Systems. NIST Special Publication, 1197. Available at: http://dx.doi.org/10.6028/NIST.SP.1197.

Government Accountability Office, 2016. Climate Change: Selected Governments Have Approached Adaptation through Laws and Long-Term Plans.

Grafakos, S., Gianoli, A. and Tsatsou, A., 2016. Towards the Development of an Integrated Sustainability and Resilience Benefits Assessment Framework of Urban Green Growth Interventions. Sustainability, 8(461), pp.1-33. 
Herrero, S.T., Ürge-Vorsat, D. and Petrichenko, K., 2013. Fuel poverty alleviation as a cobenefit of climate investments: evidence from Hungary. In European council for an energy efficient economy summer study. pp. 1605-1616.

IPCC, 2014. Climate Change 2014: Mitigation of Climate Change. Contribution of Working Group III to the Fifth Assessment Report of the Intergovernmental Panel on Climate Change, Cambridge University Press. Available at: http://www.ipcc.ch/report/ar5/wg3/.

IPCC, 2001. Climate Change 2001: Mitigation: Contribution of Working Group III to the Third Assessment Report of the Intergovernmental Panel on Climate Change, Available at: https://www.ipcc.ch/ipccreports/tar/wg3/.

Khew, Y.T.J. et al., 2015. Assessment of social perception on the contribution of hardinfrastructure for tsunami mitigation to coastal community resilience after the 2010 tsunami: Greater Concepcion area, Chile. International Journal of Disaster Risk Reduction, 13, pp.324-333. Available at: http://dx.doi.org/10.1016/j.ijdrr.2015.07.013.

Larsen, R.K., Calgaro, E. and Thomalla, F., 2011. Governing resilience building in Thailand's tourism-dependent coastal communities: Conceptualising stakeholder agency in social - ecological systems. Global Environmental Change, 21(2), pp.481-491. Available at: http://dx.doi.org/10.1016/j.gloenvcha.2010.12.009.

Lu, Y. and Stern D.I., 2016. Substitutability and the cost of climate mitigation policy. Environmental and Resource Economics, 64(1), pp.81-107. Available at: http://dx.doi.org/10.1007/s10640-015-9936-7.

Machalaba, C. et al., 2015. Climate Change and Health: Transcending Silos to Find Solutions. Annals of Global Health, 81(3), pp.445-458. Available at: http://dx.doi.org/10.1016/j.aogh.2015.08.002.

Markandya, A., Rübbelke, D.T.G. and Lavoro, N.D.I., 2004. Ancillary Benefits of Climate Policy. Journal of Economics and Statistics/Jahrbücher für Nationalökonomie und Statistik, 224(4), pp.448-503.

Mechler, R., Mochizuki, J. and Hochrainer-Stigler, S., 2016. Disaster Risk Management and Fiscal Policy: Narratives, Tools, and Evidence Associated with Assessing Fiscal Risk and Building Resilience., p.39.

Millennium Ecosystem Assessment, 2005. Ecosystems and Human Well-being, vol. 5. Island Press.

Mitchell, D., Enemark, S. and Molen, P.V.D., 2015. Climate resilient urban development: Why responsible land governance is important. Land Use Policy, 48, pp.190-198.

National Research Council, 2012. Disaster Resilience: A National Imperative, The National Academies Press. 
NIST Special Publication 1190, 2016. Community Resilience Planning Guide for Buildings and Infrastructure Systems, Vol. I and II. Available at:

http://dx.doi.org/10.6028/NIST.SP.1190v1 and http://dx.doi.org/10.6028/NIST.SP.1190v2.

Plaza-Bonilla, D. et al., 2015. Carbon management in dryland agricultural systems. A review. Agronomy for Sustainable Development, 35, pp.1319-1334.

Potts, M. et al. 2005. The pill is mightier than the sword. International Journal of Health Policy and Management, 4(8), pp. 507-510.

PPD-21, 2013. Presidential Policy Directive 21: Critical Infrastructure Security and Resilience.

PPD-8, 2011. Presidential Policy Directive 8: National Preparedness.

Rodin, J., 2014. The Resilience Dividend: Being Strong in a World Where Things Go Wrong, PublicAffairs.

Rose, A., 2016. Capturing the Co-Benefits of Disaster Risk Management on the Private Sector Side.

Saunders, W.S.A. and Becker, J.S., 2015. A discussion of resilience and sustainability: Land use planning recovery from the Canterbury earthquake sequence, New Zealand. International Journal of Disaster Risk Reduction, 14, pp.73-81. Available at:

http://dx.doi.org/10.1016/j.ijdrr.2015.01.013.

Scrieciu, S.Ş. et al., 2014. Advancing methodological thinking and practice for developmentcompatible climate policy planning. Mitigation and Adaptation Strategies for Global Change, 19(3), pp.261-288.

SDR, 2005. Grand Challenges for Disaster Reduction.

Stern, N.H., 2007. The Economics of Climate Change: The Stern Review, Cambridge University Press.

Suckall, N., Stringer, L.C. and Tompkins, E.L., 2015. Presenting Triple-Wins? Assessing Projects That Deliver Adaptation, Mitigation and Development Co-benefits in Rural SubSaharan Africa. AMBIO, 44(1), pp.34-41.

Tanner, T. et al., 2015. The Triple Dividend of Resilience: Realising development goals through the multiple benefits of disaster risk management, Overseas Development Institute, The World Bank.

Tomczyk, A.M., White, P.C.L. and Ewertowski, M.W., 2016. Effects of extreme natural events on the provision of ecosystem services in a mountain environment: The importance of 
trail design in delivering system resilience and ecosystem service co-benefits. Journal of Environmental Management, 166, pp.156-167. Available at:

http://dx.doi.org/10.1016/j.jenvman.2015.10.016.

Ürge-Vorsatz, D. et al., 2014. Measuring the Co-Benefits of Climate Change Mitigation. Annual Review of Environment and Resources, 39(October), pp.549-582. Available at: http://dx.doi.org/10.1146/annurev-environ-031312-125456.

Von Stechow, C. et al., 2015. Integrating Global Climate Change Mitigation Goals with Other Sustainability Objectives: A Synthesis. Annual Review of Environment and Resources, 40, pp.363-394. Available at: http://dx.doi.org/10.1146/annurev-environ-021113-095626.

Vorhies, F. and Wilkinson, E., 2016. Co-Benefits of Disaster Risk Management.

Wardekker, J.A. et al., 2016. Screening regional management options for their impact on climate resilience: an approach and case study in the Venen-Vechtstreek wetlands in the Netherlands. SpringerPlus, 5(1), pp.1-17.

Wenger, C., 2015. Better use and management of levees: reducing flood risk in a changing climate. Environmental Reviews, 23(2), pp.240-255. 